\title{
saience\& society
}

\section{Adequateregulation, astop-gap measure, or part of a package?}

\author{
Debates on codes of conduct for scientists could bediverting attention away from moreserious questions
} FilippaCandiusen

$\mathrm{T}$ he potential misuse of biological knowledge and research by military forces or terrorists is an increasing concern for both security experts and policy-makers. In addition to existing biosafety and biosecurity regulations that are aimed at reducing the public health and environmental risks of biological research, policy-makers feel that further measures are needed to prevent new techniques and knowledge from being used by criminals or terrorists. O ne proposed measure that has gained considerable support over the past few years is voluntary self-governance by the scientific community and, in particular, codes of conduct.

In this article, I consider how the debate on codes of conduct for bioscientists began, and outline the various ways in which different stakeholders have supported such codes. Shifting the focus from policy to practice, I explore how effective such codes for bioscientists would be as a regulatory measure, drawing from experiences of regulating recombinant DNA research in the USAanother self-governance regime. Finally, having noted a number of limitations with selfgovernance and codes of conduct, I explore why so much emphasis is currently placed on codes of conduct in the discussions on preventing misuse, and argue that there are at least three possible interpretations.

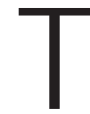
he debate about codes of conduct for bioscientists was initiated in November 2001, when the US government endorsed "a solid framework for bioscientists in the form of a code of ethical conduct that would have universal recognition" (Bush, 2001). A few weeks later, John Bolton, former
US U nder Secretary of State for Arms Control and International Security, further endorsed codes at the Fifth Review Conference of the Biological and Toxin Weapons Convention (BTWC), when he said that "a professional code of conduct for scientists working with pathogenic microorganisms [is critical and timely]" (Bolton, 2001). In December 2005, the states that were party to the BTWC discussed the content, promulgation and adoption of codes of conduct for life scientists.

\section{... policy-makers feel that further measures are needed to prevent new techniques and knowledge from being used by criminals or terrorists}

The years between the 2001 statements and the 2005 discussions saw a number of initiatives to support such codes. The National Academy of Sciences (Washington, DC, USA), for example, suggested in its report Biotechnology Research in an Age of Terrorism: Confronting the Dual-Use Dilemma that the nature of dual-use risks and the responsibilities of scientists should be outlined and added to the codes of ethics of relevant professional societies (Fink et al, 2003). This could then be supplemented by a review of experiments that raise concern about the potential for misuse. The report identified seven areas of concern, including work that would enhance the virulence of a pathogen or demonstrate how to render a vaccine ineffective. It was envisaged that the review would be added to the existing National Institutes of Health $(\mathrm{NIH}$; Bethesda,
MD, U SA) system for reviewing experiments with recombinant DNA through local biosafety committees. The Royal Society (London, UK) has had a sustained interest in the control of biological weapons and in preventing biological research from being misused. Strongly committed to self-governance by the scientific community, the Royal Society maintains that "Codes of conduct can help to reduce the risk that scientific research will be misused. The process of producing codes raises awareness amongst the target groups and fosters discussion on the potential for misuse" (Royal Society, 2005).

$O$ ther scientific organizations, including the International Centre for Genetic Engineering and Biotechnology (Trieste, Italy), the International Union of Biochemistry and Molecular Biology (Bern, Switzerland) and the International Council for the Life Sciences (Washington, DC, USA), have also supported codes of conduct. In April 2005, the American Society for Microbiology (ASM ; Washington, DC, USA) added concerns about the misuse of biological research to its code of ethics, which now states that ASM members "are obligated to discourage any use of microbiology contrary to the welfare of humankind, including the use of microbes as biological weapons" and "will call to the attention of the public or the appropriate authorities misuses of microbiology or of information derived from microbiology" (ASM, 2005). Individual scientists have also expressed support for codes of conduct, most notably Margaret Somerville and Ronald Atlas, who in March 2005 published their own "code of ethics for the life sciences" in the journal Science (Somerville $\&$ Atlas, 2005). 


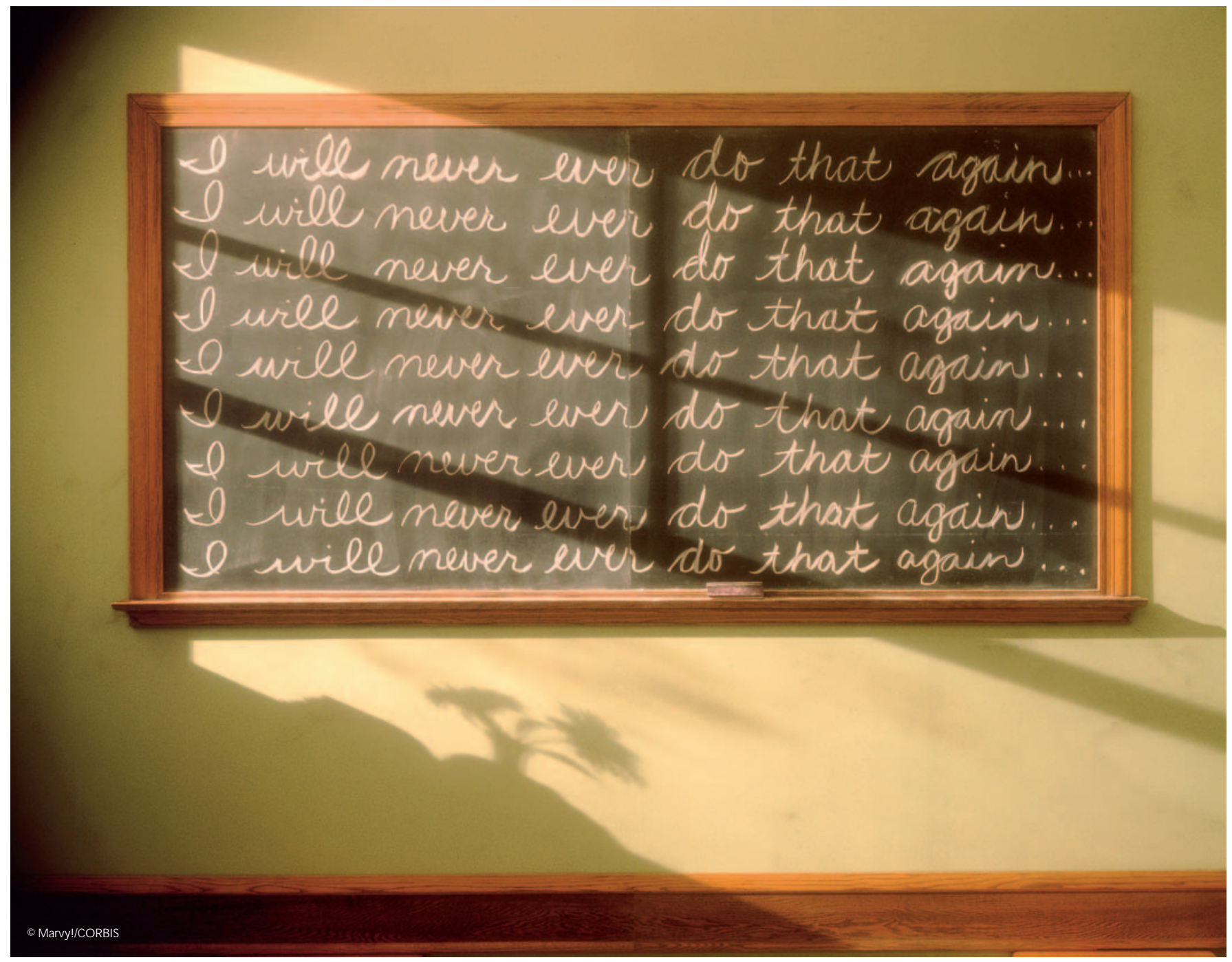

Prominent medical organizations have also voiced their support for codes of conduct in the life sciences. The World Medical Association (W MA; Ferney-Voltaire, France) urges "all who participate in biomedical research to consider the implications and possible applications of their work and to weigh carefully in the balance the pursuit of scientific knowledge with their ethical responsibilities to society" (WMA, 2002). Drawing on its experience of devising and implementing codes of ethics, it has also offered its assistance in both writing and publicizing a code of ethics to medical researchers and their colleagues (Pearson, 2005). The British Medical Association (BMA; London, UK), which published a report entitled Biotechnology, Weapons and Humanity as early as 1999 , followed by a second edition in 2004, notes that "Professional scientists and physicians have an ethical responsibility to reinforce the central norm that biological and genetic weapons are unacceptable. This should be explicitly stated in codes of professional conduct in order to safeguard the public interest in matters of health and safety" (BMA, 1999). The American Medical Association (Chicago, IL, USA) has drawn up guidelines to prevent the malevolent use of biomedical research, in which researchers are asked to assess foreseeable ramifications and balance benefits against potential harms from corrupt application of the findings.

Various intergovernmental organizations have also supported codes of conduct, including the U nited Nations Educational, Scientific and Cultural O rganization (Paris, France), the O rganisation for Economic Cooperation and Development (OECD; Paris, France) and the International Committee of the Red Cross (ICRC; Geneva, Switzerland).
The OECD, for instance, has set up a website to provide a global information resource on codes of conduct for the bioscience research community, and the ICRC has called on the scientific and medical communities and industry "to adopt professional and industrial codes of conduct aimed at preventing the abuse of biological agents" (ICRC, 2002).

1 he December 2005 meeting of the 155 states that are party to the BTW C endorsed codes of conduct, agreeing that they can make "a significant and effective contribution, in conjunction with other measures, to combating the present and future threats posed by biological weapons and bioterrorism" (BTWC, 2005). Significantly, it was noted that codes of conduct should be "regularly reviewed, evaluated for effectiveness, and revised as necessary". This was one of the first policy statements on 
codes of conduct to address the issue of effectiveness. Yet, although the report drew attention to effectiveness in terms of the scope, substance and requirements of codes, it did not question the effectiveness of codes as a regulatory measure to prevent the misuse of biological research.

In fact, so far, we know little about how codes of conduct in biological research operate in practice. We can gain some insight, however, from other more familiar voluntary guidelines, such as the $\mathrm{NIH}$ Guidelines for Research Involving Recombinant DNA Molecules, which regulate the genetic modification of organisms. These guidelines are a useful example of a voluntary self-governance regime, not only because they are widely applicable and we have almost three decades of experience with their implementation, but also because their remit is being considered for expansion to include concerns about potential misuse.

\section{... to date, we know little about how codes of conduct in biological research operate in practice}

The NIH guidelines were introduced in 1976, soon after genetic modification became a tool for biological research, and have since undergone a number of amendments. Today, researchers who receive $\mathrm{NIH}$ grants are required to follow the guidelines, whereas others at both public and private institutions are encouraged to do so on a voluntary basis. Among other things, the $\mathrm{NIH}$ guidelines require institutions to establish institutional biosafety committees (IBCS) to review and approve recombinant DNA research. The review process includes independent assessment of the facilities and containment levels that are required, as well as the procedures for training personnel who are involved in the research. When possible, institutions are encouraged to open their IBC meetings to the public and are obliged, upon request, to make the minutes from such meetings freely available.

O ne of the first surveys to investigate how IBCs operate in practice was conducted soon after the $\mathrm{NIH}$ guidelines were first implemented (Dutton \& Hochheimer, 1982). As part of the survey, questionnaires were sent to the chairs of the 20 IBCs that were registered in California in June 1980; of the 19 committees that responded, two were private companies. The survey found variation in both the structure of the committees and how they worked. The committee sizes ranged from 7 to 16 members, whereas biologists working with recombinant DNA comprised from $9 \%$ to $58 \%$ of each committee. In the year before the survey was undertaken, five of the IBCs had met once every three months, several had not met at all and one had met 15 times. Eight of the IBCs reported no regularly scheduled meetings. About one-third of the IBCs conducted some business by telephone or letter, with several functioning almost exclusively in this way.

The survey also found variation regarding the approval of research projects. Several IBCs did not review any research proposals in 1979, whereas one reviewed 68. Of the 19 IBCs questioned, 11 had rejected none of the proposals considered. Significantly, the survey found that the two corporate IBCs approved the largest proportion of the proposals submitted, required the fewest modifications and had the lowest rejection rates (that is, no rejections).

Finally, the survey highlighted a lack of public access to these meetings. In fact, most had done little to encourage public participation and many had actively discouraged it. O nly one IBC reported receiving requests for minutes. The two corporate IBCs reported restricting the agenda of their meetings because of proprietary concerns. In a larger national survey, many corporate IBCs reported that meetings were not open to the general public (Dutton \& Hochheimer, 1982).

A nother survey of IBCs, which was carried out more than 20 years later, focused on the public access aspect (The Sunshine Project, 2004). Through a request under the US Freedom of Information Act, an electronic spreadsheet was obtained from the NIH Office of Biotechnology Activities, which included contact information for the 439 IBCs that were registered with the NIH at that time. The contact details for 49 of these committees were incomplete or proved to be incorrect, but the remaining 390 were contacted with requests for the minutes of their two most recent meetings, and a reminder of the $\mathrm{NIH}$ requirement to make minutes available to the public.

Eight months after the first contact, 276 of the IBCs had responded, but not all had provided meeting minutes. Some provided documents that were described as minutes, but were in fact too atypical to evaluate. A Massachusetts-based biotechnology firm replied, for instance, by sending a laboratory inspection checklist that was used by a local public health agency, claiming it to be the IBC minutes. Others provided irrelevant information. In the end, minutes from 199 of the IBCs were evaluated. Of these, only 15 were deemed adequate, 127 failed outright to provide satisfactory disclosure (most of them severely) and 57 were better but still unacceptable.

\section{Lack of access to IBC meetings and minutes, for example, hinders public monitoring of research activities and limits accountability}

Biotechnology is exploited most intensively in commercial enterprises. This is also where the potential for misuse is most acute, as a result of heavy investments in both intellectual property and highly specialized equipment. In terms of industry, the survey found that only about 70 firms had NIHregistered IBCS. According to estimates by Ernst \& Young (2005), the US biotechnology industry comprises about 1,500 companies. Not all of these conduct recombinant DNA research; nevertheless, 70 seems an unexpectedly low figure. Of the 70 firms, only 26 responded to the survey, 14 of which provided minutes. None of the minutes were deemed to provide adequate disclosure.

The survey further revealed that some private sector IBCs did not review specific research projects, but instead issued blanket approvals without regard for individual project details. It also showed that the N IH had received a number of 'inactivation requests' or requests to be removed from their registry. A typical example read: "Hoffmann-La Roche no longer conducts research that is subject to the NIH guidelines... by virtue of having no N IH funding for our recombinant DNA activities. At this time we choose not to register our IBC with the NIH" (The Sunshine Project, 2004). The same report cites Merck as stating "We currently do not perform any research or manufacturing that requires IBC overview, the committee has therefore been dissolved", IDEC Pharmaceuticals as stating that the company "is no longer conducting research subject to the NIH guidelines, and its IBC has therefore been discontinued", and so on. 
$\mathrm{B}$ uilding on the 1982 and 2004 surveys, I conducted interviews with a number of junior and senior scientists and biosafety officers at 13 biotechnology firms in California, as part of a larger study looking at the impact of biosafety and biosecurity regulations. The firms on which I focused were established mainly during the past 5-10 years-although three of the larger firms were established in the 1980s. The size of the companies ranged from 4 to more than 5,000 employees and all worked on pathogens or disease-causing biological agents. Most of the companies had biodefence contracts through either the $\mathrm{NIH}$ or the US D epartment of D efense.

\section{Preventing these state-level programmesin the future should therefore be a primary concern, rather than implementing codes of conduct for life scientists}

Briefly, the survey found that four firms did not have IBCs, but one of these companies did not use recombinant DNA in its research activities. Of the nine firms with IBCs, four had NIH -registered committees. This suggests that a number of firms have IBCs but do not necessarily register them with the NIH. In line with the 1982 survey, great variation was observed in how the IBCs operated. There was variation in the stage of the company life cycle at which the IBCs were formed, the number of committee members and the number of members who were external to the company. There was also variation in the frequency of meetings and how they were conducted: some committees met in person, whereas others interacted through video conferences or by e-mail. Similarly to the 2004 study, it was found that some of the IBCs issued blanket approvals, whereas others reviewed individual proposals. The survey also highlighted what seemed to be a low rejection rate for proposals - none of the informants had ever had a project rejected or had heard of a project being rejected. In fact, one of the biosafety officers I spoke to said that the purpose of IBCs was not to approve or reject proposals, but rather to make sure the projects would be conducted safely: "The IBC is a partner with the research scientists in how they set themselves up to be successful. O ne of the things we tell the people who bring project proposals to the IBC is that we're not an approval agency. We're not an approval body. We're here to make sure that your safety protocols and your environmental protocols are sound, so that your people can make this product make money for us." Finally, and unsurprisingly given intellectual property considerations, the IBC meetings were not open to the general public.

T his preliminary sketch of how IBCS operate is indicative, rather than representative, of how voluntary selfgovernance regimes, such as the NIH guidelines, function in practice in the biosciences. It demonstrates that the operation of IBCs is not straightforward. There is variation in when IBCs are set up, their structure, the frequency of meetings and how they meet, the quality of minutes produced and whether they approve individual projects or groups of projects. Different IBCs interpret their purpose and responsibilities differently. A number of institutions do not have IBCs, some do but do not register them with the $\mathrm{NIH}$, and others are actively taking them off the NIH registry. It seems highly likely that codes of conduct would, in practice, also face such inconsistencies, not only between different countries and different institutions, but also between different laboratories within the same institution, between different research teams and even between different individuals on the same team.

\section{... the current sole focus on codes... might well serveto detract from other more crucial regulatory measures that target not only individual scientists but also state programmes}

Of particular concern is the restriction of public access to the decision-making process. Lack of access to IBC meetings and minutes, for example, hinders public monitoring of research activities and limits accountability. Indeed, the lack of input into the discussions on the misuse of biological research from people outside the scientific community is already of concern. We have learned from the recombinant DNA policy debates of the late 1970s and early 1980s that keeping discussions strictly within the scientific community concentrates the focus on technical issues, at the expense of broader social and ethical concerns (Wright, 1994). In the same way that the policy debates on recombinant DNA were progressively limited to the short-term risks of using this technology in basic research, while ignoring wider concerns such as industrial-scale or military uses, we are running the risk that major interests are being permitted to shape or even control the focus of our discussions.

$\mathrm{P}$ ursuing this idea further, we can ask why voluntary self-governance regimesand codes of conduct in particularare being given so much attention in policy discussions about preventing the misuse of biological research when they appear to have significant shortcomings in practice. Indeed, why have individual scientists become the target of the policy discussions when it is generally accepted within the disarmament community that the greatest risk of misuse is at the level of national biological weapons programmes? Matthew Meselson and Julian Robinson (2002) noted that, historically, the most technologically advanced and large-scale preparations for the use of biological weapons were made as part of the military offensive biological weapons programmes of the twentieth century, particularly in the UK, USA and former USSR. Preventing these state-level programmes in the future should therefore be a primary concern, rather than implementing codes of conduct for life scientists. Furthermore, although the BTWC permits defensive programmes, the proliferation of secret 'offensively orientated' defence programmes should also be a major concern.

Such programmes have already come to light in the USA. O ne project, which was carried out by the Central Intelligence Agency (Fairfax, VA, USA), involved constructing a cluster munition $\approx$ based on fragments of a Soviet biomunition, to disseminate bacterial pathogens and testing the weapon using non-pathogenic agents (Miller et al, 2001). Another project, which was conducted by the US Defense Threat Reduction Agency, tested whether terrorists could construct a sophisticated bioweapons plant from commercially available materials without raising suspicions (Miller etal, 2001). As M eselson \& Robinson (2002) observed: "There is a grave danger that secret, offensively oriented, defence programmes will acquire a momentum of their own, proliferating and eventually becoming offensive programmes."

Their concerns regarding both state-level offensive programmes and offensively orientated defensive programmes are echoed by others in the disarmament community 
who are looking at the threat of bioterrorism and biological weapons (Guillemin, 2005; Wheelis \& Dando, 2002). It is therefore valid to question whether the focus on researchers in scientific institutions and private companies is misplaced, and whether the primary concern should actually be directed at state-run programmes.

$\mathrm{R}$ eturning to the question of why so much attention is given to individual scientists and codes of conduct, there are at least three possible interpretations. The first is that a number of policy makers believe that codes of conduct could help to raise awareness, promote best practice, build trust, reinforce the norm against the use of biological weapons, and therefore provide an adequate response to address the potential for misuse.

The second interpretation is that codes of conduct are operating as a stop-gap measure. In July 2001, the US administration withdrew from the seven-year negotiations for a legally binding, and widely supported, verification and compliance protocol to strengthen the BTW C - which, to date, has no organization, budget, or inspection and sanctioning provisions-and left the international community with little choice but to put multilateral negotiations on hold. At best, the rejection signalled the start of the Bush administration's unilateral and confrontational approach to counter the threat of biological weapons and bioterrorism, and a return to Reagan-era policies that were characterized by the use of force and technology for the purpose of national security (Guillemin, 2005). Worse, it raised the possibility that the USA has "new classified biodefence programmes that are deemed too sensitive politically or technically for even the limited disclosure that the protocol would require" (Wheelis \& Dando, 2002). W orse still is the prospect that the USA "currently has secret, offensively-oriented 'biodefence' programmes [that] it is committed to continuing and to expanding..." (Wheelis \& Dando, 2002).

Shortly after its withdrawal from the negotiations, the Bush administration also sought to disband the ad hoc group deliberating the protocol. This unexpected announcement, which was made less than two hours before the Fifth Review Conference of the BTWC was scheduled to end in December 2001, jeopardized the whole conference and progress towards agreement of a final declaration. To avoid complete failure, the conference was adjourned for a year. When the discussion resumed in November 2002, a set of meetings leading up to the Sixth Review Conference in 2006 was agreed on, as a compromise, to continue discussions on strengthening the BTWC. However, the discussion topics were limited to subjects that did not concern military or commercial interests-the two primary reasons that the Bush administration gave for rejecting the protocol. It could be argued that the function of these meetings has primarily been to keep the international dialogue going by concentrating on fringe topics, such as codes of conduct, until there is a change of administration and the USA comes back to the table. The policy focus on a voluntary regulatory regime and codes of conduct is, therefore, less about creating an effective regulatory regime in practice, and more about buying time before discussions on tackling the threat from national biological weapons programmes can be resumed.

$\mathrm{T}$ he third, and perhaps less cynical, interpretation is that policy makers believe codes of conduct are an important contribution to prevent the misuse of biological research, butcould only ever function as an effective regulatory measure in conjunction with other procedures that are backed by some form of sanctions, such as the declarations, on-site visits and challenge inspections outlined in the failed protocol to the convention. The 2005 report on the content, promulgation and adoption of codes of conduct would certainly suggest that this is the case. Yet, although this seems to be the most reasonable answer to the question of why so much attention is dedicated to individual scientists and codes of conduct in the present policy discussions, we should note that the current sole focus on codes, and the extensive investment of resources that accompanies it, might well serve to detract from other more crucial regulatory measures that target not only individual scientists but also state programmes. Without this plurality of regulatory measures in place, codes of conduct are doomed to fail.

\section{REFERENCES}

ASM (2005) Code of Ethics. Washington, DC, USA: American Society for M icrobiology

BM A (1999) Biotechnology, Weapons and Humanity. London, UK: BM A

Bolton JR (2001) US Statement on the Fifth Review Conference of the Biological Weapons

Convention. N ov 19. www.acronym.org.uk/ bwc/revconus.htm

BTW C (2005) Synthesis of Considerations, Lessons, Perspectives, Recommendations,
Conclusions and Proposals D rawn from the Presentations, Statements, Working Papers and Interventions on the Topic Under Discussion at the M eeting of Experts (BWC/M SP/2005/L.1). Geneva, Switzerland: BTW C

Bush GW (2001) President's Statement on Biological Weapons. N ov 1. Washington, DC, USA: The White House

Dutton D B, H ochheimer JL (1982) Institutional biosafety committees and public participation: assessing an experiment. $N$ ature 297: 11-15

Ernst \& Young (2005) Beyond Borders: G lobal Biotechnology Report 2005. N ew York, NY, USA: Ernst \& Young

Fink GR, Atlas R, Franz D (2003) Biotechnology Research in an Age of Terrorism: Confronting the 'Dual-U se' Dilemma. Washington, DC, USA: $N$ ational Academies Press

Guillemin J (2005) Biological Weapons: From the Invention of State-Sponsored Programs to Contemporary Bioterrorism. N ew York, NY, USA: Columbia U niversity Press

ICRC (2002) Appeal on Biotechnology, Weapons and Humanity. Geneva, Switzerland: ICRC

Meselson M, Robinson JP (2002) Preventing the hostile use of biotechnology: the way forward now. CBW Conventions Bull 57: 1-2

Miller J, Engelberg S, Broad W (2001) Germs: Biological Weapons and America's Secret War. N ew York, NY, USA: Simon \& Schuster

Pearson GS (2005)The biological weapons convention meeting of experts. CBW Conventions Bull 68: 12-19

Royal Society (2005) The Roles of Codes of Conduct in Preventing the Misuse of Scientific Research. RS Policy D ocument 3/05. London, U K: Royal Society

Somerville MA, Atlas RM (2005) Ethics: a weapon to counter bioterrorism. Science 307: 1881-1882

The Sunshine Project (2004) M andate for Failure: The State of Institutional Biosafety Committees in an Age of Biological Weapons Research. Austin, TX, USA: The Sunshine Project

Wheelis M, Dando M (2002) On the brink: biodefence, biotechnology and the future of weapons control. CBW Conventions Bull 58: 3-7

W MA (2002) The World Medical Association Declaration of Washington on Biological Weapons. Ferney-Voltaire, France: W M A W right S (1994) M olecular Politics: Developing American and British Regulatory Policy for Genetic Engineering, 1972-1982. Chicago, IL, USA: U niversity of Chicago Press

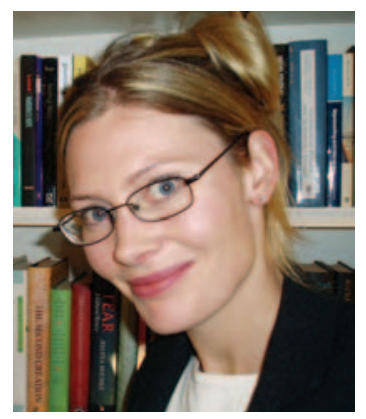

Filippa Corneliussen is at the London School of Economics, London, UK.

E-mail: f.corneliussen@lse.ac.uk

doi:10.1038/sj.embor.7400683 